Bulletin d'Histoire Contemporaine de I'Espagne

$54 \mid 2020$

Les espaces du politique dans l'Espagne du Trienio liberal (1820-1823)

\title{
Bartolomé Bennassar (1929-2018)
}

Joseph Pérez, Université de Bordeaux III. Ancien Directeur de la Casa de Velázquez. Premio Príncipe de Asturias et Ciencias Sociales 2014

\section{OpenEdition}

1 Journals

Édition électronique

URL : http://journals.openedition.org/bhce/3298

DOI : $10.4000 /$ bhce.3298

ISSN : 1968-3723

Éditeur

Presses Universitaires de Provence

Édition imprimée

Date de publication : 1 janvier 2020

ISSN : 0987-4135

Référence électronique

Joseph Pérez, Université de Bordeaux III. Ancien Directeur de la Casa de Velázquez. Premio Príncipe de Asturias et Ciencias Sociales 2014, « Bartolomé Bennassar (1929-2018) », Bulletin d'Histoire

Contemporaine de l'Espagne [En ligne], 54 | 2020, mis en ligne le 01 juillet 2020, consulté le 30

décembre 2020. URL : http://journals.openedition.org/bhce/3298 ; DOI : https://doi.org/10.4000/bhce. 3298

Ce document a été généré automatiquement le 30 décembre 2020.

Bulletin d'histoire contemporaine de l'Espagne 


\title{
Bartolomé Bennassar (1929-2018)
}

\author{
Joseph Pérez, Université de Bordeaux III. Ancien Directeur de la Casa de \\ Velázquez. Premio Príncipe de Asturias et Ciencias Sociales 2014
}

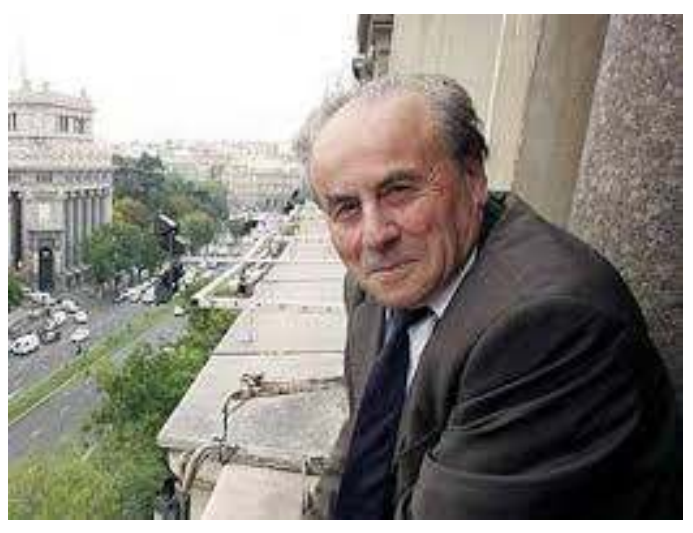

(c) Archives BHCE

2 Bartolomé Bennassar (1929-2018), professeur à l'université de Toulouse - Le Mirail, dont il a été le président de 1978 à 1980, a consacré ses recherches à l'Espagne, à son passé, à son mode de vie, à ses passions. Deux périodes ont retenu son attention : celle de la prépondérance -le siècle d'or- et celle de la guerre civile et de Franco.

Un livre domine la première période : la thèse sur Valladolid dirigée par Fernand Braudel et soutenue en 1967. Qu'on ne s'y trompe pas : c'est beaucoup plus qu'une banale histoire urbaine. L'évolution de Valladolid à l'époque moderne résume l'évolution de toute l'Espagne ou, plus exactement, d'une monarchie qui comprend alors, non seulement la couronne de Castille, mais aussi la couronne d'Aragon -avec le royaume de Naples-, les Pays-Bas, la Franche-Comté et les vice-royautés d'Amérique. Où se situe le centre vital de cette monarchie ? À l'intérieur d'une bande de deux cents kilomètres de large environ qui va du Cantabrique à l'Atlantique. Dans ce couloir se trouvent les ports -Santander et Bilbao, au nord, Séville, au sud-, les villes commerciales -Burgos et son Consulat, Séville et sa Casa de la Contratación-, les centres d'affaires -Medina del Campo-, les industries -Ségovie, Cuenca, Tolède-, les terres à blé -la Tierra de Campos autour de Palencia -, les trois grandes universités : 
Salamanque, siège de la scolastique rénovée par Francisco de Vitoria, autour du collège dominicain de Saint-Etienne, Valladolid, foyer de l'Espagne militante -c'est au collège de Saint-Paul que s'est formé Las Casas ; c'est à Valladolid que se tient la confrontation sur la colonisation-, Alcalá, enfin, spécialisée dans la théologie positive et l'humanisme ; autant de villes rivales de Valladolid. Pourtant, Valladolid les surpassera toutes car elle bénéficie des faveurs de la monarchie. Elle n'est pas la capitale, mais les Cortès de Castille s'y réunissent souvent ; le roi et la cour y font de fréquents séjours. Valladolid va suivre le destin collectif de la monarchie et l'illustrer. Située au cœur de l'Espagne - à l'époque, on disait : el riñón de España -, dans cette Meseta qui a été le moteur de la Reconquête, elle voit peu à peu son rôle diminuer : inexorablement, le sud l'emporte sur le nord; Séville prend de plus en plus de place dans l'économie de l'Espagne à cause du commerce avec les Indes et Burgos perd sa suprématie en raison de la révolte des Pays-Bas. Philippe II en tire la conséquence : il établit sa capitale à Madrid, toujours sur l'axe central, mais au sud du Guadarrama; Valladolid capitale, c'était la survivance de l'Espagne reconquérante; Madrid capitale, c'est une Espagne nouvelle, à l'heure de l'Amérique et du péril turc.

4 Valladolid est le siège de la Chancellerie qui juge en appel de toutes les décisions rendues par les tribunaux au nord du Guadarrama, ce qui suppose des magistrats, des notaires, des avocats, des plaideurs qu'il faut loger, nourrir, distraire; des milliers de personnes vivent de l'activité de ce tribunal. Valladolid devient une ville de letrados, d'hommes de lois, plus que de négociants; seule une minorité se consacre à la production. Valladolid voit le triomphe du tertiaire : on y vit du travail des campagnes voisines, des grands domaines qui fournissent aux nobles des revenus considérables, des dépenses de la cour, des salaires versés aux fonctionnaires; c'est une ville de rentiers, de courtisans, d'officiers royaux, d'ecclésiastiques. Nous touchons là à l'apport le plus neuf de la thèse : juros et censos, la dette publique et les emprunts privés font vivre Valladolid et bientôt toute la Castille. C'est par cet aspect que l'exemple de Valladolid est représentatif du destin de l'Espagne. Certes, Valladolid n'est pas toute la Castille: Burgos, et Ségovie offrent une autre image; l'une était tournée vers le commerce international, l'autre vers l'industrie textile; elles signalent la voie qu'aurait pu prendre l'Espagne si elle n'avait pas été entraînée par la tentation de la rente. La situation s'aggrave au XVIIe siècle : Burgos, Valladolid, Tolède... deviennent des villesmusées; la Castille se dépeuple. Ce qu'on appelle à tort la décadence -la période 1620-1680-, c'est peut-être, comme disait Pierre Vilar, le temps mort pendant lequel la Meseta s'immobilise alors que les Espagnes périphériques n'ont pas encore pris le relais.

5 Ces recherches sur l'Espagne du Siècle d'or, Bennassar les complète par des études de cas: Don Juan d'Autriche, Velázquez, Hernán Cortés, et par des analyses particulièrement percutantes, l'une sur l'Inquisition (1979), les deux autres, écrites en collaboration avec sa femme Lucile, sur 1492 (1991) et sur ce phénomène typique du monde méditerranéen : les conversions à l'Islam à la suite de circonstances fortuites le plus souvent, la captivité.

6 Sur Franco, les recherches de Bennassar peuvent se résumer ainsi : un général qui a pris la tête d'un coup de force qui s'était organisé sans lui, un politique qui s'impose comme chef d'un parti dont il n'était pas membre, un homme d'Etat qui tient tête à Hitler, en octobre 1940, qui, en 1945, fait face à l'hostilité du monde libre et des Nations Unies, qui désigne son successeur et qui réussit le tour de force de mourir dans son lit, 
cet homme a été un dictateur sans pitié pour ses opposants ; ce n'était sûrement pas un imbécile.

7 En marge de ses préoccupations principales, Bennassar s'est intéressé aux voyageurs français en Espagne (1998, en collaboration avec sa femme), à l'histoire de Madrid et à l'histoire du Brésil (2000).

8 Bartolomé Bennassar n'a pas été seulement un professeur et un chercheur. Il a été aussi un aficionado averti -on lui doit une Histoire de la tauromachie (1993) - et un romancier : il est notamment l'auteur du Baptême du mort (1962), qui est porté à l'écran en 1970 sous le titre Le Dernier saut, par Edouard Luntz, avec Michel Bouquet et Maurice Ronet, et du Coup de midi (1964).

9 Le Bulletin d'Histoire Contemporaine de l'Espagne, qui prit la suite du Bulletin du Département de Recherches Hispaniques créé par Manuel Tunón de Lara à l'université de Pau, a été fondé par l'équipe de contemporanéistes du GRECO 30 du CNRS dirigé par Bartolomé Bennassar et put voir le jour grâce à l'appui de celui-ci et de Joseph Pérez, alors directeur de la Maison des Pays Ibériques à l'université de Bordeaux. 